\title{
SPRUCE REGENERATION IN NORTHERN ONTARIO
}

\author{
By J. B. Millar,
}

Forester, Wm. Bonifas Lumber Company

\section{INTRODUCTION}

THIS paper is based on eight years' work in Northern Ontario. It con-

cerns principally Black Spruce, in pure stands or mixed with White

Spruce, Balsam, and Poplar. While the studies were confined to the

Great Clay Belt of Ontario, subsequent observations indicate that they would apply farther west in Ontario and in the northern part of the Lake States wherever Black Spruce forms a merchantable stand.

The work was done by a pulp and paper company to obtain the basic data required in the formation of a plan of management that would ensure a perpetual supply of pulpwood for their mill. From inventory and operating cruises, the amount of merchantable wood and the extent of immature stands were known for each watershed. The problem, therefore, was to procure:

1. Yield tables for the immature stands;

2. Information regarding recent burns, including species present, degree of stocking, and probable growth rates;

3. Regeneration and growth on the cut-overs.

The first part was accomplished by laying out sample plots in stands of various ages from 25 to 120 years, with their remeasurement every five years. From this, yield tables were prepared. However, at the moment, we are considering Spruce regeneration only. A logical subdivision would be

a. Regeneration after fire

b. Regeneration after cutting.

\section{REGENERATION AFTER FIRE}

Few people realize how important forest fires have been in the development of our pulpwood stands. For example, in a recent cruise of some 2,000 square miles, it was estimated that 78 per cent. of the area had been burned in the last 120 years. There had been at least seven extensive fires since 1820. (Do not think that I am criticizing the Ontario Forestry Branch. The worst fire, covering almost 1,000 square miles-nearly half the area in question-occurred about 1870 . The present administration can hardly be blamed for that.) The point I want to emphasize is that these fires have been beneficial; they have rejuvenated the pulpwood stands and today these burns carry our best stands of Black Spruce. From a number of studies made in these even-aged forests, we have arrived at several conclusions regarding the result of fire. Some of the following statements may be questioned and rightly so because we cannot prove them statistically. They may be only theory but repeated observations support them and we believe them at present. 
First, Black Spruce is primarily a fire-type. Possibly, I should qualify that and say that the best commercial stands of Black Spruce are the result of fire. The swamps, Spruce flats, and merchantable muskegs which predominate in that section of Ontario invariably regenerate to Spruce following a fire. Other species are noticeably absent.

On the higher, well-drained areas, which are considerably less in extent, the Black Spruce does not enjoy such a monopoly. Poplar, White Birch, and White Spruce are commonly found with it after the fire. However, if the previous stand contained no Spruce, that is, consisted of hardwood and Bal. sam, or if the previous stand was less than 40 years old, a fire does not produce Spruce; which brings us to the origin of the Spruce or the source of seed. Previously, it was thought that seed was stored in the duff and litter on the forest floor to a depth not reached by fire and this seed provided in a large measure the new crop. If such were the case, why does not Balsam comprise part of the new stand? Likewise, in a burned cut-over, Spruce should be abundant but instead is completely missing. We now believe that the seed comes from the standing, fire-killed timber. This was forcibly brought to our attention in the winter of 1932 . While going through an area burned the previous spring, abundant seed was noticed on the snow. The margin of green timber was too far away to supply the seed and the distribution was fairly uniform over the area, another argument against the idea that the seed was from living trees. Further investigation revealed a supply of seed in the cones grouped at the top of the Black Spruce. Some time later, seed was collected and germinated from trees dead at least a year. The germination per cent. was very low, but still there was viable seed present.

As mentioned already, when a cut-over area is burned, the chances of getting coniferous reproduction are very slight. Four separate areas which had been treated in this manner were examined in detail. The time of the fire varied as to season and, also, with respect to cutting, from immediately following logging up to a period of 18 months after the cutting. Even five years after the fire, no Spruce or Balsam reproduction could be found. Poplar, White Birch, Pin Cherry, and Alder had complete control of the area.

When a young stand is burned, the results are similar to those in a cutover. Since the Spruce in the original stand was not old enough to produce seed, the new crop will be composed of hardwood and weed species only. I have in mind a pronounced example of this: A mature stand was burned in 1923. It reproduced very nicely and a fine new growth of Spruce was well started when a second fire occurred in 1929. Due to a creek and a heavy rain at the right moment, the second fire was checked before it got beyond the boundary of the original fire. Eight years later the whole area was 
covered by brush from 6-10 feet high, but it was possible to trace accurately the limit of the second fire entirely by the presence or absence of Spruce reproduction. Nowhere on the area twice-burned was there a single Spruce seedling.

Let me summarize briefly the results of fire. The presence of Black Spruce in a burn is directly influenced by the drainage, age, and condition of the original stand. Following a fire, the reproduction will be

1. On a cut-over area-No Spruce.

2. In a young stand-No Spruce.

3. On well-drained sites-Spruce, both Black and White, with Poplar and Birch.

4. In poorly drained swamps and muskegs-Black Spruce exclusively. REGENERATION AFTER CUTTING

In the pulpwood stands of northern Ontario, only a clear-cutting system has been practiced to any extent. All Spruce and Balsam to a minimum stump diameter of 5 inches is cut. Beginning in 1933 and continuing each spring since then, a regeneration survey has been made to determine the amount and condition of advance growth left from the previous stand and the amount, species, and distribution of new reproduction. The survey covers a period of about two weeks each spring between the time the snow melts and the leaves come out. Each year the work is confined to areas cut five years previously. It is assumed that in the intervening years the heaviest mortality from sun-scald and wind-throw will have occurred. The advance growth which has not recovered by the end of that period seems to have a poor chance of survival and is not included in the tally.

The first year a strip tally system was used, with a total count on a $3.3^{\prime}$ strip, separate tally for each chain, making a continuous series of transects. The results, converted to a per-acre basis, were quite high but gave no idea of distribution. Since then, the stocked quadrat method had been used with a complete tally on every tenth quadrat. The quadrats are $1 / 600$ th of an acre and are tallied as stocked or not, with additional notes as to species, size, and age of reproduction. The quadrats are taken at one chain intervals along compassed lines.

The results were much better than anticipated. Considering Balsam with the Spruce, over the whole area, $89 \%$ of the quadrats are stocked, which is quite good. Spruce alone is found on $68 \%$ of the quadrats, the difference being mainly on the well-drained areas. If we would be satisfied with a mixture of Spruce and Balsam, the results from clear-cutting would be satisfactory for where the percentage of Spruce is down, Balsam is most prevalent. However, the mill has stringent limitations on the amount of Balsam accepted and so we feel that any increase in the percentage of Balsam in the next stand is detrimental to the company. 
With the object of increasing the amount of Spruce regeneration, we are now conducting experiments in the various ways of cutting. The worst stand, from the viewpoint of Spruce, will be the mixed highland types. The possible methods here are limited. Planting, of course, would be the surest and in some isolated areas of small extent will be the only hope. Present indications are that an increased diameter limit will be the most advantageous change in the promotion of Spruce regeneration. The development of a market for Poplar would also be of material assistance. At present the only Poplar utilized is for the lumber in camp construction, which necessarily affects only a very limited area. If economic conditions would permit the removal of the hardwoods, the increased opening of the stand would benefit Spruce at the expense of the Balsam. Where there is less Poplar originally, the regeneration of Spruce is better.

In the swamps and merchantable muskegs, the stocking of Spruce is quite adequate for the next rotation with the exception of one minor subdivision. This is where the original stand is even-aged, even-sized, pure, Black Spruce with practically no advance growth present at the time of cutting. Usually the cordage is much better than average with, as a result, a very heavy cover of slash. Due to the lack of advance growth and this thick slash, the present cutting method is not considered satisfactory. As a test, one area has been covered by a clear-cut strip method. Strips, two chains wide, running across the prevailing wind direction, are alternately cut clean or left standing. The area was cut during the first year's operation of a new camp. It is planned to remove the remaining strips the last year from the same camp. This will give three or possibly four years for the first cut to seed in. We realize that the period is short, and that no provision is made for stocking the second half. There is also the danger of serious wind-throw. Preliminary experiments in Northern Minnesota indicate that wind-throw may not be as serious as is usually considered. This system, even theoretically, is not completely satisfactory. However, we feel that it is an improvement and any change from the present will be for the good.

We have realized all along that different phases of our research program could possibly have been carried out in a better manner. If we had the unlimited time, and more complete equipment available to the Government organizations, then more suitable methods might have been used, more detailed work done on the sample plots, and more extensive cutting experiments carried on. But the practical aspect has been continually in the forefront. Any experimental work must have a connection with future dividends, and that connection must be quite apparent. I am not apologizing in any way for defects in our methods or for work not attempted. We feel that suitable progress has been made and that the studies completed will, to some small extent at least, assist in stabilizing the pulp and paper industry. 